\title{
Composite Materials Manufactured by Photopolymer 3D Printing with Metal-Organic Frameworks
}

\author{
A. I. Cherevko ${ }^{a}, b$, G. L. Denisov ${ }^{a}$, I. A. Nikovskii ${ }^{a}$, A. V. Polezhaev ${ }^{a}$, \\ A. A. Korlyukov ${ }^{a}$, and V. V. Novikov ${ }^{a, b}, *$ \\ ${ }^{a}$ Nesmeyanov Institute of Organoelement Compounds, Russian Academy of Sciences, Moscow, Russia \\ ${ }^{b}$ Moscow Institute of Physics and Technology, Dolgoprudnyi, Moscow oblast, Russia \\ *e-mail: novikov84@ineos.ac.ru
}

Received July 29, 2020; revised August 24, 2020; accepted September 1, 2020

\begin{abstract}
New composite materials containing metal-organic framework (MOF-5) particles were manufactured by $3 \mathrm{D}$ printing. The optimal composition of the photopolymer formulation and printing conditions ensuring the highest quality of printing were selected. Retention of the metal-organic framework (MOF) structure in the resulting composite objects was demonstrated by powder X-ray diffraction. The distribution of MOF-5 particles over the whole bulk of the 3D product was studied by X-ray computed tomography. In the future, composite materials of this type containing catalytically active MOFs, with their structure and properties being controllable at the micro and macro levels, could find application as catalysts of various chemical processes.
\end{abstract}

Keywords: porous metal-organic frameworks, composite materials, photopolymer 3D printing

DOI: $10.1134 / \mathrm{S} 107032842105002 \mathrm{X}$

\section{INTRODUCTION}

Metal-organic frameworks (MOFs) [1] possess a number of unique properties (first of all, low density and high porosity [2]) and, hence, they are actively used for gas storage [3] and separation [4] and as materials for nonlinear optics [5], sensorics [6], magnetism [7], medicinal chemistry [8], and catalysis [9]. Despite the wide variety of MOF-based catalysts, virtually each of them can be classified into one of three types, in which the catalytic site is (a) located on the metal ion in the metal-containing unit, (b) bound to an organic linker, or (c) encapsulated inside the pores.

In view of a number of advantages of such catalysts over conventional catalytic materials (first of all, the absence of a dead volume, which accounts for exceptionally efficient diffusion of substrate molecules in the MOF pores), in recent years, numerous attempts have been made to switch from the use of MOF-based catalysts in research laboratories to their practical use in modern industrial plants. However, despite the progress attained in scaling-up of synthetic approaches, which made some MOFs commercially available, the crystalline nature of these products hampers their application as catalysts of real industrial processes. Indeed, the use of polycrystalline powders in industry is faced with difficulties such as the high pressure loss for a fluid flow across a dense layer, generation of dust, attrition, and fouling [10]. For this reason, the fabrication of products with a desired shape containing porous MOF particles is a challenging problem, which is tackled by numerous research teams $[11,12]$. In particular, approaches to manufacturing MOF-containing products as granules [13], films [14], hollow microspheres [15], blocks [16], gels [17], foams [18], paper sheets [19], and solid blocks [20] have been developed to date. However, particular catalytic applications impose stringent requirements on the micro- and macrostructures of catalytic materials, which cannot be formed, in some cases, by conventional methods.

One of the methods suitable for manufacturing arbitrarily shaped products with high spatial resolution is $3 \mathrm{D}$ printing [21], implemented as two most popular versions: fused deposition modeling (FDM) and stereolithography (SLA). In the FDM technique, a 3D object of a desired shape is formed via layer-by-layer extrusion of thermoplastic filament according to a digital model, while SLA is based on layer-by-layer polymerization of a light-sensitive formulation under the action of a laser beam or using a conventional digital projector or a light-emitting diode array as the light source (so-called digital light processing (DLP) technique).

In most cases, MOF particles were introduced into 3D-printed products by one of the three possible approaches: deposition of MOF particles on already printed objects, direct printing with MOF using a 
binder, or printing with a composite material containing MOF particles.

Metal-organic framework deposition on already printed objects to fabricate a composite product has been reported previously [22-31]. For example, liquid-phase epitaxial growth of HKUST-1 MOF particles on FDM-printed acrylonitrile/butadiene/styrene templates gave rise to objects capable of reversible adsorption of methylene blue from solutions [22]. In a series of studies, the research team headed by Fernando Maya proposed and successfully tested a method for attaching various particles (ranging from adsorbents for extraction of uranium(IV) [23], chromium(VI) [24], and other pollutants [25] to porous MOF particles [26]) on DLP 3D-printed objects. The method is based on direct deposition of desired particles on freshly manufactured products, the surface of which bears the residual photopolymer composition, followed by UV irradiation, which results in ultimate polymerization and sticking of deposited particles on the surface (stick \& cure method). However, manufacture of objects with a complex inner geometry using this approach is faced with some difficulties.

Another approach to obtaining products with embedded MOF particles is direct printing with a paste-like material, which is prepared by mixing MOF with various binders and which is extruded into the shape of the desired object. In some cases, a photopolymer is incorporated into the binder, which allows curing of the product to be conducted immediately after extrusion. The most interesting examples are compositions containing UiO-66 particles in the photopolymer for the catalytic conversion of the pesticide methyl paraoxon [27], ZIF-8 mixed with cellulose nanofibers for printing of a curcumin-adsorbing gel [28], ZIF-8 with methylcellulose and bentonite for the isolation of biobutanol [29], and materials for liquid chromatography based on MOFs entrapped by polysaccharide or gelatin matrices [30]. Mention should also be made of direct printing of HKUST-1 in the absence of any binder [31]. Although this method allows fast fabrication of MOF-containing composite products, their spatial resolution is very low. This is related to the nature of paste-like binder used as the matrix for MOF particles.

Finally, one more approach implies the use of a 3D printing technique characterized by relatively high spatial resolution such as FDM or SLA with expendable materials (thermoplastic filaments or light curing resins) that already contain MOF particles. FDM 3D printers are used most often (in particular, in the chemical scientific community for the manufacture of chemical ware [32, 33], photoreactors [34], electrolytic cells [35], and other laboratory equipment [36, 37]) due to their accessibility and easy operation. However, their use for the fabrication of 3D objects from composite materials containing porous MOF particles is complicated, because it is difficult to prepare the initial composite filament and because 3D printing must be performed at high temperature at which MOF can decompose. Conversely, SLA is free from the indicated drawbacks and, hence, it is suitable for manufacturing arbitrarily shaped 3D products, including those made of composite materials. However, currently, there is only one published example of successful application of SLA technique for 3D printing with composite materials containing MOF particles [38]. In the reported study, it was demonstrated that controlled photopolymerization of a formulation containing, apart from acrylic monomers, the wellknown metal organic framework HKUST-1 may generate the desired distribution of polymer particles in an intricately shaped 3D object without a noticeable loss of adsorption capacity and with simultaneous increase in its stability, in particular, to hydrolysis. In the present study, we made an attempt to use a similar approach for another popular MOF representativeMOF-5.

\section{EXPERIMENTAL}

Synthesis of MOF. Micro-sized MOF-5 particles were prepared by a known procedure [39] by the reaction of terephthalic acid with zinc(II) acetate monohydrate in DMF in the presence of triethyamine. The obtained particles were separated on a filter, dispersed in DMF $(250 \mathrm{~mL})$, kept for $24 \mathrm{~h}$, separated on a filter once again, dispersed in dichloromethane $(350 \mathrm{~mL})$, and kept for 12 days, with the solvent being replaced every 3 days. The precipitate that formed was separated on a filter and dried at reduced pressure $(10 \mathrm{~mm}$ $\mathrm{Hg}$ ) for $24 \mathrm{~h}$. The phase composition of the obtained MOF was confirmed by powder X-ray diffraction.

Powder X-ray diffraction. X-ray diffraction patterns of MOF samples and manufactured composite samples were measured on a Bruker D8 Advance diffractometer $\left(\mathrm{Cu} K_{\alpha 1}\right.$ radiation, $\left.\lambda=1.5406 \AA\right)$ equipped with a Ge220 monochromator, a fixed slit aperture, and a position-sensitive Lynx Eye detector. Phase analysis was performed using the DIFFRAC.Topas program [40].

Thermogravimetric (TG) analysis was carried out on a NETZH TG 209 F1 Libra instrument in the temperature range from 30 to $550^{\circ} \mathrm{C}$ at a heating/cooling rate of $10 \mathrm{~K} \mathrm{~min}^{-1}$ in a argon atmosphere.

The scanning electron microscopy (SEM) images of samples placed on a $25-\mathrm{mm}$ aluminum stage and attached with a conductive carbon tape were recorded in the secondary electron mode at an accelerating voltage of $15 \mathrm{kV}$ on a Phenom ProX instrument.

A full-size sample $(10 \times 10 \times 4 \mathrm{~mm})$ was placed on the sample holder of a Bruker SkyScan 1172 X-ray micrograph (Belgium). The set of shadow projections of the sample was obtained in the micro-CT scanning mode (voltage of $40 \mathrm{kV}$, current of $100 \mathrm{~mA}$, resolution of $1.5 \mu \mathrm{m}$, rotation step of $0.05 \mathrm{deg}$, exposure time of 

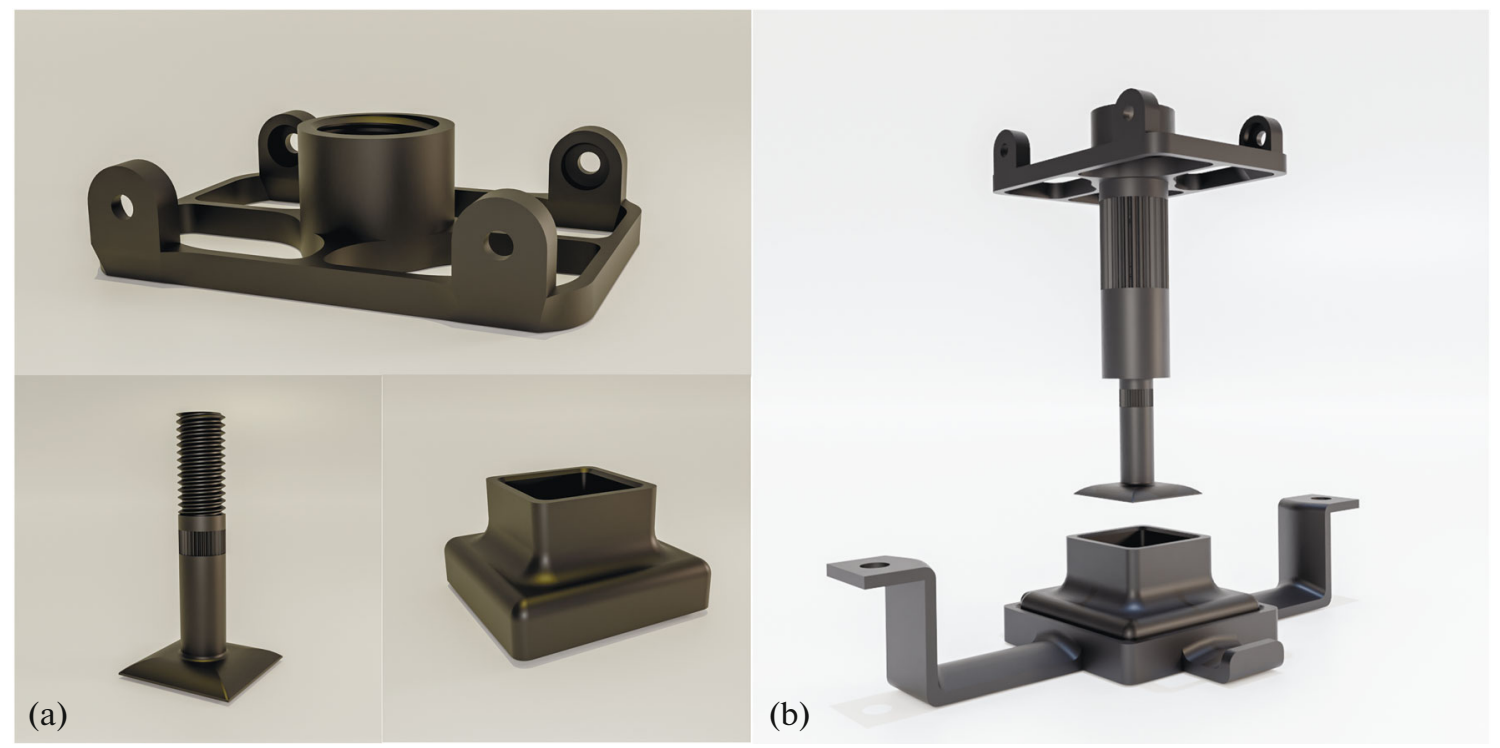

Fig. 1. 3D models of parts used for modification of the 3D printer: (a) glass fixing elements and resin bath; (b) whole assembly.

$2400 \mathrm{~ms}$, and scanning time of $8.5 \mathrm{~h}$ ) using the SkyScan software.

The 3D printing was carried out with a commercial Wanhao DUPLICATOR 7 PLUS photopolymer DLP $3 \mathrm{D}$ printer modified for reducing the consumption of MOF. Solving of current problems did not require complete redesign of the printer; therefore, it was decided to change the design of some parts. A modular design was chosen, which made it possible to rapidly replace single parts in the case of failure and to test various prototypes and soon use them if necessary. This approach was suitable for fast evaluation of particular engineering solutions. Models of the parts used to modify the commercial 3D printer are depicted in Fig. 1. The models in the stl format are available from the authors on request.

For manufacturing the above parts of the 3D printer, frequently used $3 \mathrm{D}$ printing materials were chosen, namely, ABS (acrylonitrile/butadiene/styrene) and PET-G (polyethylene glycol terephthalate). The latter demonstrated high stability to all photopolymer resins used in the study. The bottom of the bath for the photopolymer was made of readily available fluorinated ethylene/propylene film, which well transmits ultraviolet light in the range above $351 \mathrm{~nm}$ and virtually does not decrease the printing quality. Instead of polished aluminum, which is used in the commercial 3D printer as the support for the first printed layer, a glass plate requiring no additional treatment and exhibiting excellent adhesion properties was chosen in this case. The design of all parts was performed in the Autodesk Fusion 360 system according to educational license.

The photopolymer formulation was based on commercially available Wanhao Industrial Blend resin. The resin and MOF particles were mixed using a
UZD2-0.1/22 ultrasonic homogenizer $(15-5 \mathrm{kHz}$ vibration frequency) at room temperature for 10 $15 \mathrm{~min}$. The obtained suspensions did not show visual phase separation for $48 \mathrm{~h}$. For determining the maximum content of MOF particles in the photopolymer resin that provided a satisfactory quality of $3 \mathrm{D}$ printing, the particle concentration was gradually increased starting from $1 \mathrm{wt} \%$. For each particular composition, the optimal conditions for 3D printing were selected. Combinations of simple geometrical figures were used as visual 3D printing objects, which allowed for fast calibration of printing. Table 1 summarizes the key printing parameters that ensured the best quality of printing for the obtained photopolymer formulations.

\section{RESULTS AND DISCUSSION}

The 3D printer modification markedly accelerated the DLP 3D printing of three-dimensional objects

Table 1. Parameters of printing of three-dimensional objects with a photopolymer resin filled with MOF-5 particles

\begin{tabular}{c|c|c|c}
\hline $\begin{array}{c}\text { Content of MOF-5 } \\
\text { in the photopolymer } \\
\text { resin, \% }\end{array}$ & $\begin{array}{c}\text { Exposure } \\
\text { time of one } \\
\text { layer, s }\end{array}$ & $\begin{array}{c}\text { Exposure } \\
\text { time of initial } \\
\text { layers, s }\end{array}$ & $\begin{array}{c}\text { Number } \\
\text { of initial } \\
\text { layers }\end{array}$ \\
\hline 1 & 20 & 28 & 10 \\
2 & 20 & 28 & 10 \\
3 & 23 & 29 & 10 \\
4 & 22 & 28 & 10 \\
5 & 17 & 24 & 10 \\
10 & 9 & 16 & 10 \\
15 & 8 & 16 & 10 \\
20 & 9 & 16 & 10 \\
\hline
\end{tabular}

Vol. $47 \quad$ No. $5 \quad 2021$ 


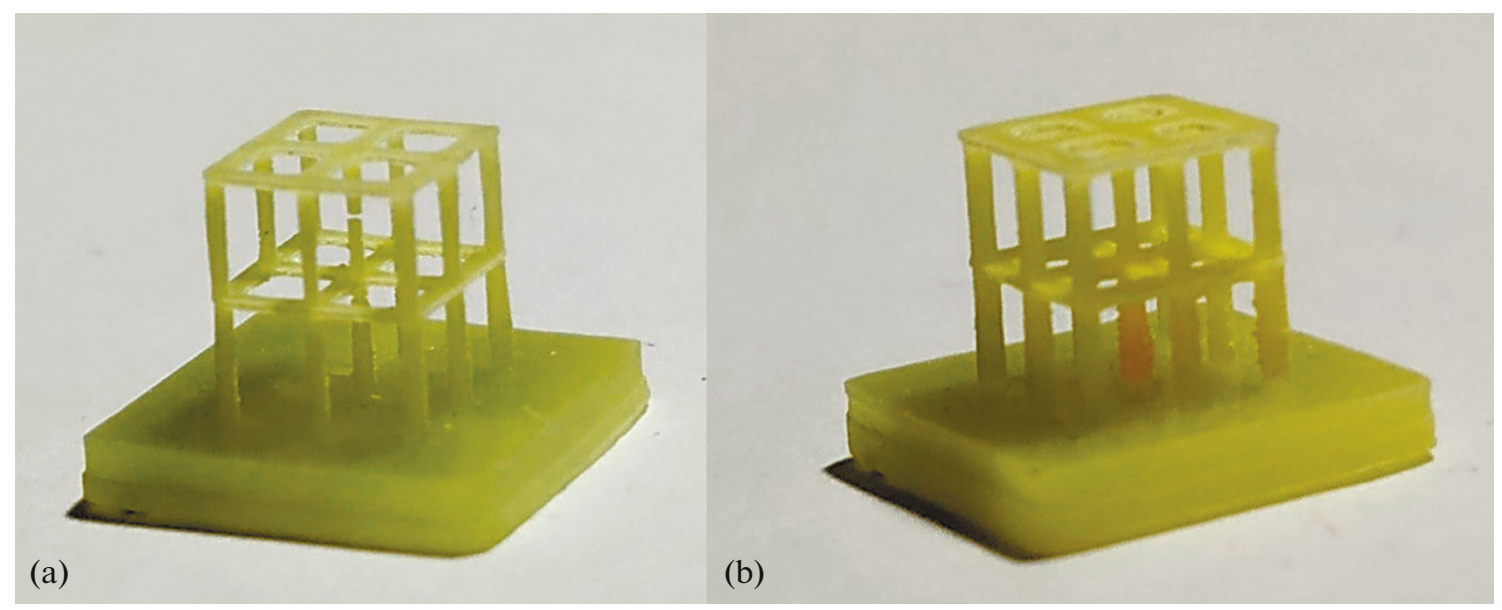

Fig. 2. Photographs of the three-dimensional objects containing MOF-5 particles: (a) 5, (b) 10 wt $\%$. The dimensions of the object base is $10 \times 10 \mathrm{~mm}$.

with considerable decrease in the consumption of expendable materials. This enabled thorough adjustment of the optimal composition of the photopolymer resin and $3 \mathrm{D}$ printing conditions. In particular, for decreasing the consumption of photopolymer and composite formulation components, the resin bath was modified. The dimensions of the initial bath were $90 \times 147 \times 30 \mathrm{~mm}$, which resulted in an unreasonably large consumption of photopolymer resin components and, what is more important, MOF particles. This problem was solved by manufacturing a smaller bath $(25 \times 25 \times 30 \mathrm{~mm})$. As a result, the consumption of expendables per printing cycle decreased more than 20 -fold.

During selection of optimal 3D printing parameters, it was found that the shortest exposure time required for each layer in the presence of $10 \mathrm{wt} \%$ MOF-5 particles in the composition was $9 \mathrm{~s}$. The $3 \mathrm{D}$ objects demonstrated good spatial resolution and uniformity of $3 \mathrm{D}$ printing, which made it possible to manufacture products of a rather complex shape (Fig. 2). Thus, the presence of MOF-5 particles did not cause a pronounced increase in the exposure time of each layer due to light scattering by the particles.

The structure and properties of the resulting 3D composite products were studied by powder X-ray diffraction, SEM, X-ray computer tomography, and TG analysis.

Figure 3 shows the X-ray diffraction patterns of MOF-5 and the obtained nanocomposite. The polymer base of the composite does not form a crystalline phase and gives rise to a wide amorphous halo. The crystallite size of this phase calculated in terms of the column height distribution from the integral broadening was 133(18) $\mathrm{nm}$ [41]. According to powder X-ray diffraction data, the incorporation of MOF-5 particles into composite materials did not result in the loss of crystallinity or in some changes in the phase composition during 3D printing, as shown in Fig. 3.
The surface structure of the composites containing MOF-5 particles was characterized by SEM. Examination of the MOF-containing 3D objects showed the presence of particles of different size distributed rather uniformly over the object surface (Fig. 4). The bright surface areas were assigned to MOF-5 particles on the basis of energy dispersive spectroscopy data (Fig. 5).

The MOF-5 particle size distribution in the polymer matrix after completion of the 3D-printing was studied by X-ray computed tomography. A detailed representation of the tomography data is given in the video available on the Internet [https://tinyurl. com/mof-dlp]. Although the particles are distributed rather uniformly throughout the bulk of the 3D printed products, there is some clustering, the degree of which depends on the time of ultrasonic homogenization of the sample. It is noteworthy that this is not the optimal distribution for the intended application of the manufactured composite products, because it hampers the access of reactants to catalytically active MOF particles. Indeed, in the preliminary experiments on the adsorption of fluorescein and eosin from aqueous solutions, the data of electronic spectroscopy showed that incorporation of MOF-5 particles into the photopolymer matrix considerably decreases their adsorption capacity, this effect being less pronounced for 3D products with fine structure.

Thus, despite the fact that photopolymer 3D printing can effectively manufacture composite 3D products containing MOF particles, a significant proportion of these particles is not exposed to the environment. This deteriorates the prospects for practical use of these materials in catalysis, and any successful engineering application of these materials is impossible without preliminary removal of a considerable part of the photopolymer or its conversion to the porous form. A possible solution to this problem is preliminary annealing of the objects in order to induce selective transformation of the photopolymer. According to thermogravimetric analysis, the obtained composite 


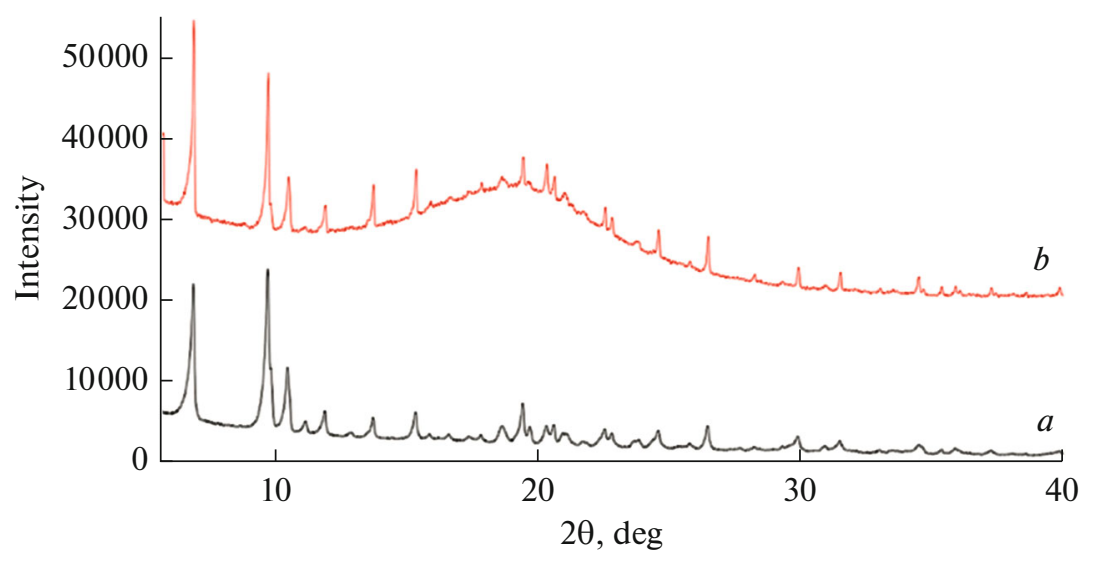

Fig. 3. X-ray diffraction patterns of the $(a)$ initial MOF-5 mixture and $(b)$ sample of the 3D-printed composite material.
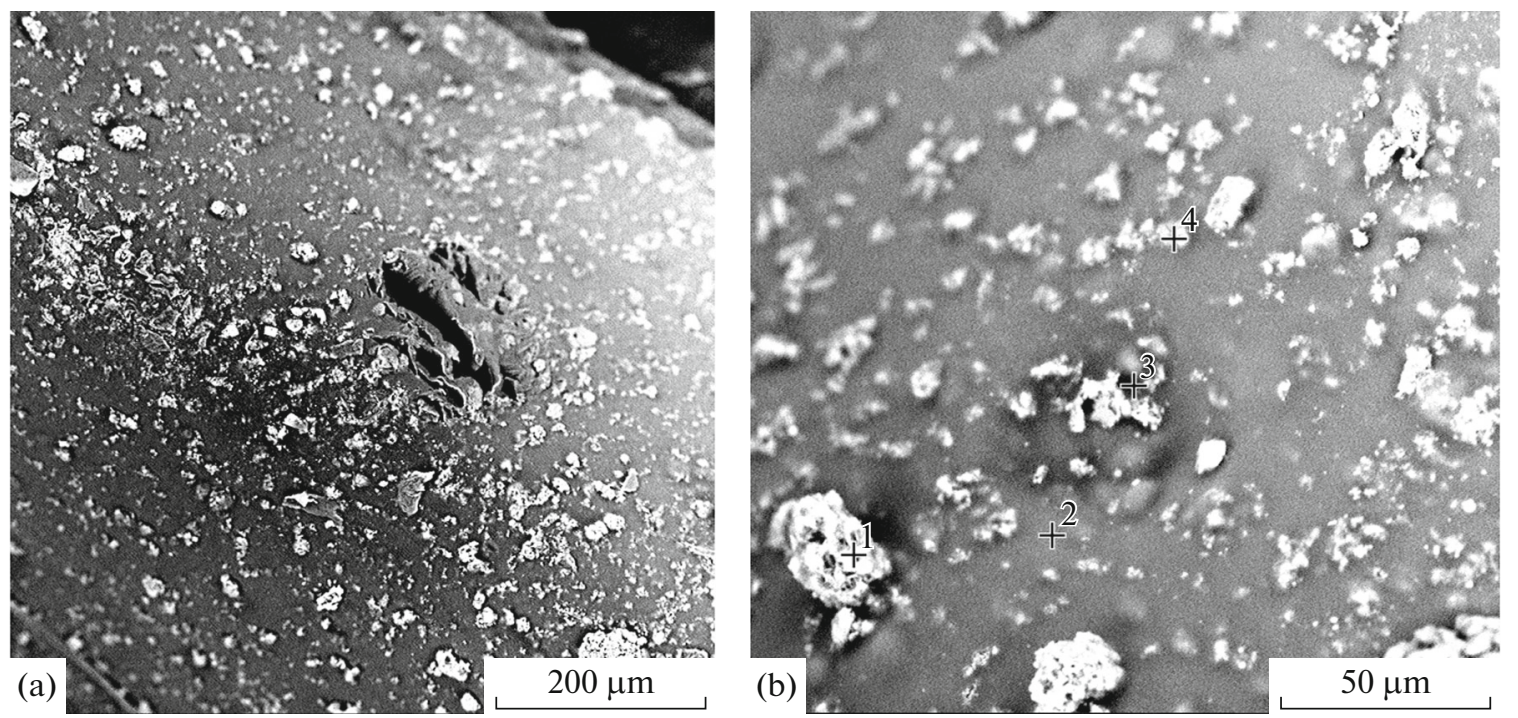

Fig. 4. Fragments of the surface of the object made of the composite material with embedded MOF-5 particles ( 2 wt \%) shown on different scales (a) 200 and (b) $50 \mu \mathrm{m}$.

3D objects are fairly thermally stable and retain $95 \%$ of their weight up to $264^{\circ} \mathrm{C}$. On heating above this temperature, intense decomposition of the photopolymer starts, leading to $90 \%$ weight loss at $450^{\circ} \mathrm{C}$ (Fig. 6). Since the thermal stability of MOF-5 is above this temperature [42], thorough selection of the conditions for low-temperature pyrolysis may allow MOF particles to be retained in the carbon matrix formed during this heat treatment.

As a result of this study, we developed approaches to the fabrication of new MOF-based hybrid materials with controlled micro- and macrostructure. Using these approaches, composite photopolymer formulations incorporating MOF-5 particles were manufactured. The compositions were used for $3 \mathrm{D}$ printing of intricately shaped objects and were characterized by a set of modern physical investigation methods.

The developed approaches to 3D-printing with photopolymer formulations can be used to manufac- ture new composite materials possessing catalytic activity in various chemical processes (including potentially industrial ones), the structure and properties of which could be controlled at both micro and macro levels. Nevertheless, the application of these materials, although possible, does not seem appropriate today due to the uniform distribution of MOF particles throughout the polymer matrix and, accordingly, shielding of most particles from the environment. A possible solution to this problem is thermal decomposition of the photopolymer resin, which would leave MOF particles unaffected. Our research team is performing studies along this line.

\section{ACKNOWLEDGMENTS}

$\mathrm{X}$-ray diffraction analysis was carried out using research equipment of the Center for Investigation of Molecular Structure of the Nesmeyanov Institute of Organoelement Compounds, Russian Academy of Sciences, supported by 
(a)

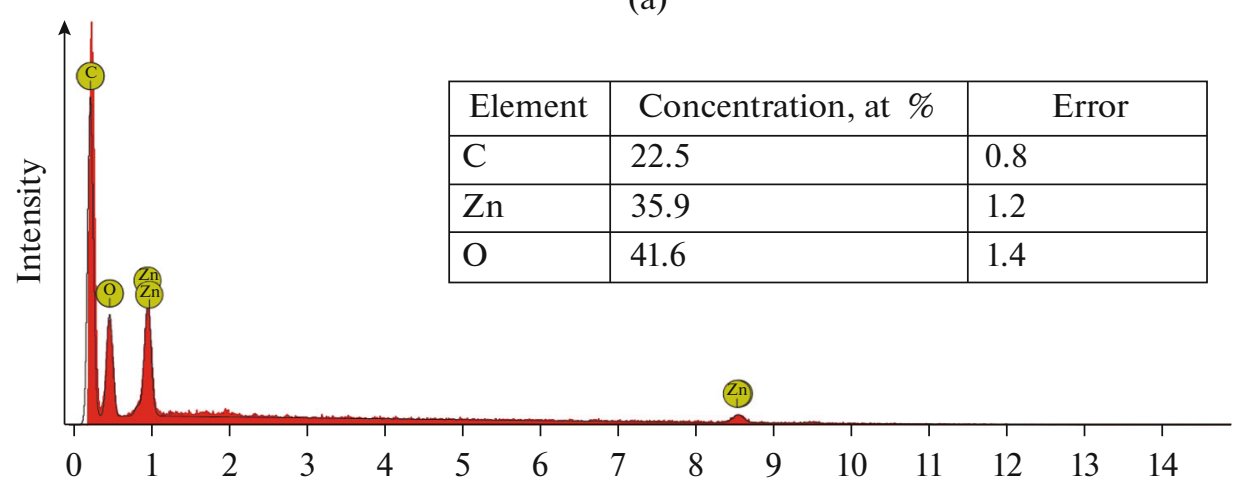

(b)

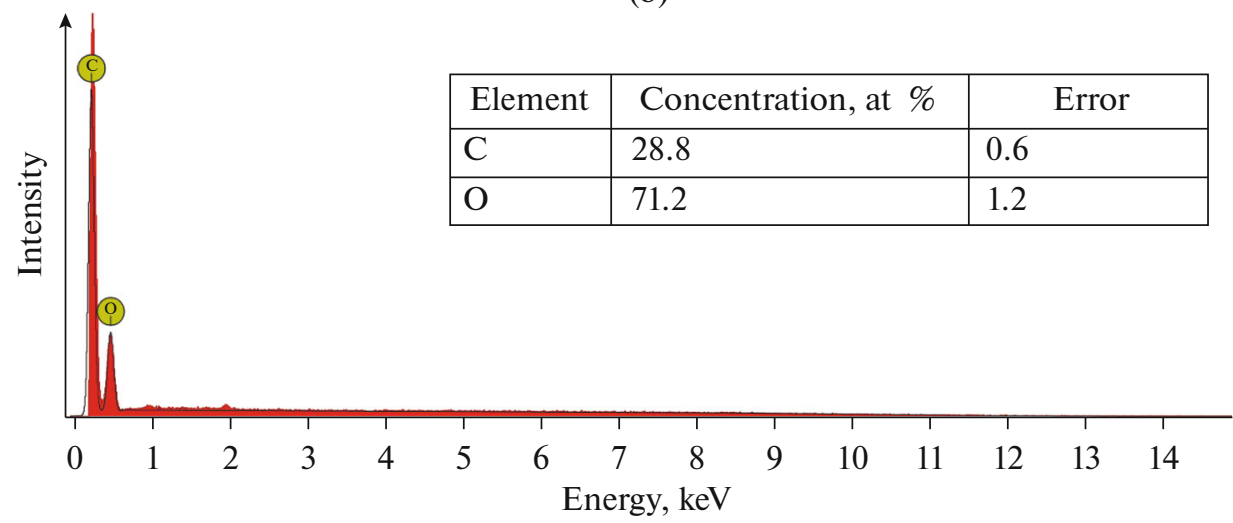

Fig. 5. Energy dispersive spectra of fragments of the surface (a) containing and (b) not containing MOF-5 particles and the corresponding elemental compositions.

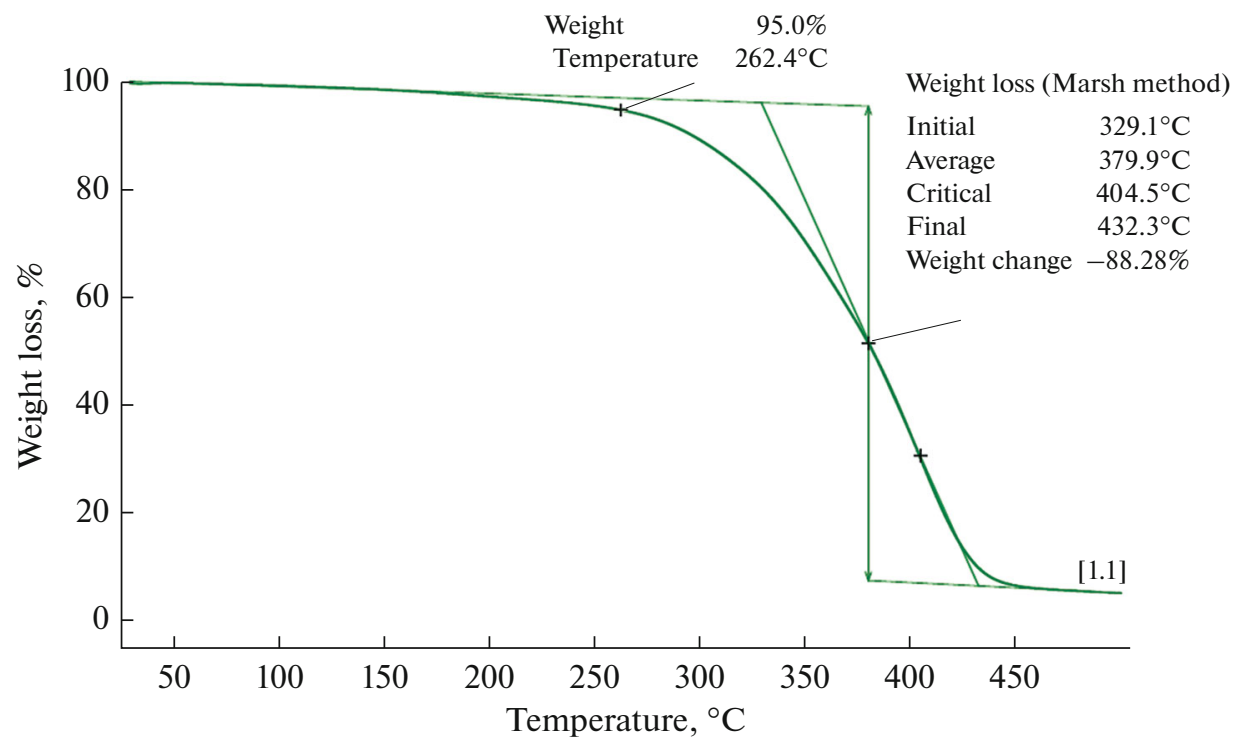

Fig. 6. Curve of weight loss of the composite material containing MOF-5 particles (2 wt \%). 
the Ministry of Science and Higher Education of the Russian Federation.

\section{FUNDING}

This study was supported by the Russian Foundation for Basic Research (grant no. 18-29-04020).

\section{CONFLICT OF INTEREST}

The authors declare that there is no conflicts of interest.

\section{OPEN ACCESS}

This article is licensed under a Creative Commons Attribution 4.0 International License, which permits use, sharing, adaptation, distribution and reproduction in any medium or format, as long as you give appropriate credit to the original author(s) and the source, provide a link to the Creative Commons licence, and indicate if changes were made. The images or other third party material in this article are included in the article's Creative Commons licence, unless indicated otherwise in a credit line to the material. If material is not included in the article's Creative Commons licence and your intended use is not permitted by statutory regulation or exceeds the permitted use, you will need to obtain permission directly from the copyright holder. To view a copy of this licence, visit http://creativecommons.org/licenses/by/4.0/.

\section{REFERENCES}

1. Yaghi, O. and Li, H., J. Am. Chem. Soc., 1995, vol. 117, no. 41, p. 10401.

2. Li, H., Eddaoudi, M., O'Keeffe, M., et al., Nature, 1999, vol. 402, no. 6759, p. 276.

3. Wilmer, C.E., Leaf, M., Lee, C.Y., et al., Nat. Chem., 2012, vol. 4, no. 2, p. 83.

4. Herm, Z.R., Wiers, B.M., Mason, J.A., et al., Science, 2013, vol. 340, no. 6135, p. 960.

5. Mingabudinova, L., Vinogradov, V., Milichko, V., et al., Chem. Soc. Rev., 2016, vol. 45, no. 19, p. 5408.

6. Gladysiak, A., Nguyen, T.N., Navarro, J.A., et al., Chem.-Eur. J., 2017, vol. 23, no. 55, p. 13602.

7. Kurmoo, M., Chem. Soc. Rev., 2009, vol. 38, no. 5, p. 1353.

8. Horcajada, P., Chalati, T., Serre, C., et al., Nat. Mater., 2010, vol. 9, no. 2, p. 172.

9. Wu, C.D. and Zhao, M., Adv. Mater., 2017, vol. 29, no. 14 , p. 1605446.

10. Iveson, S.M., Litster, J.D., Hapgood, K., et al., Powder Technol., 2001, vol. 117, nos. 1-2, p. 3.

11. Valizadeh, B., Nguyen, T.N., and Stylianou, K.C., Polyhedron, 2018, vol. 145, p. 1.

12. Liu, X.-M., Xie, L.-H., and Wu, Y., Inorg. Chem. Front., 2020, vol. 7, p. 2840.

13. Ren, J., Musyoka, N.M., Langmi, H.W., et al., Int. J. Hydrog. Energy, 2015, vol. 40, no. 13, p. 4617.

14. Moreira, M.A., Santos, J.O.C., Ferreira, A.F., et al., Langmuir, 2012, vol. 28, no. 13, p. 5715.

15. Wu, Y.-N., Li, F., Liu, H., et al., Chem. Mater., 2012, vol. 22, no. 33, p. 16971.
16. Bueken, B., Van Velthoven, N., Willhammar, T., et al., Chem. Sci., 2017, vol. 8, no. 5, p. 3939.

17. Chen, Y., Huang, X., Zhang, S., et al., J. Am. Chem. Soc., 2016, vol. 138, no. 34, p. 10810.

18. Garai, B., Mallick, A., and Banerjee, R., Chem. Sci., 2016, vol. 7, no. 3, p. 2195.

19. Küsgens, P., Zgaverdea, A., Fritz, H.G., et al., J. Am. Ceram. Soc., 2010, vol. 93, no. 9, p. 2476.

20. Carné-Sánchez, A., Imaz, I., Cano-Sarabia, M., et al., Nat. Chem., 2013, vol. 5, no. 3, p. 203.

21. Symes, M.D., Kitson, P.J., Yan, J., et al., Nat. Chem., 2012, vol. 4, no. 5, p. 349.

22. Wang, Z., Wang, J., Li, M., et al., Sci. Rep., 2014, vol. 4, p. 5939.

23. Ceballos, M.R., Serra, F.G., Estela, J.M., et al., Talanta, 2019, vol. 196, p. 510.

24. Calderilla, C., Maya, F., Cerdà, V., et al., Talanta, 2019, vol. 202, p. 67.

25. Medina, D.A., Figuerola, A., Rodriguez, F., et al., Appl. Mater. Today, 2019, vol. 14, p. 29.

26. Chen, L., Kätelhön, E., and Compton, R.G., Appl. Mater. Today, 2019, vol. 16, p. 141.

27. Young, A.J., Guillet-Nicolas, R., Marshall, E.S., et al., ChemComm, 2019, vol. 55, no. 15, p. 2190.

28. Zhang, M., Li, L., Lin, Q., et al., J. Am. Chem. Soc., 2019, vol. 141, no. 13, p. 5154.

29. Lefevere, J., Claessens, B., Mullens, S., et al., ACS Appl. Nano Mater., 2019, vol. 2, no. 8, p. 4991.

30. Satskaya, Y.A., Sotnik, S., Lagoshnyak, D., et al., Russ J. Coord. Chem., 2020, vol. 46, no. 5, p. 350. https://doi.org/10.1134/S1070328420050061

31. Lim, G.J., Wu, Y., Shah, B.B., et al., ACS Mater. Lett., 2019, vol. 1, no. 1, p. 147.

32. Gordeev, E., Degtyareva, E., and Ananikov, V., Russ. Chem. Bull., 2016, vol. 65, no. 6, p. 1637.

33. Kitson, P.J., Marie, G., Francoia, J.-P., et al., Science, 2018, vol. 359, no. 6373, p. 314.

34. Zalesskiy, S.S., Shlapakov, N.S., and Ananikov, V.P., Chem. Sci., 2016, vol. 7, no. 11, p. 6740.

35. Chisholm, G., Kitson, P.J., Kirkaldy, N.D., et al., Energy Environ. Sci., 2014, vol. 7, no. 9, p. 3026.

36. Zhang, C., Wijnen, B., and Pearce, J.M., J. Lab. Autom., 2016, vol. 21, no. 4, p. 517.

37. Denisov, G., Primakov, P., Korlyukov, A., et al., Russ. J. Coord. Chem., 2019, vol. 45, no. 12, p. 836. https://doi.org/10.1134/S1070328419120030

38. Halevi, O., Tan, J.M., Lee, P.S., et al., Adv. Sustain. Syst., 2018, vol. 2, no. 2, p. 1700150.

39. Tranchemontagne, D.J., Hunt, J.R., and Yaghi, O.M., Tetrahedron, 2008, vol. 64, no. 36, p. 8553.

40. DIFFRACplus TOPAS. Technical Reference. DOCM88-EXX066. V4.2-01, Karlsruhe: Bruker AXS, 2009.

41. Balzar, D., IUCr Monographs on Crystallography, 1999, vol. 10, p. 94.

42. Mohamed, S.A., Chong, S., and Kim, J., J. Phys. Chem. C, 2019, vol. 123, no. 49, p. 29686.

Translated by $Z$. Svitanko 